\title{
DETECTION OF VARIATION IN THE RIBOSOMAL RNA GENE CLUSTERS BY A MODIFIED FLUORESCENCE IN SITU HYBRIDIZATION METHOD
}

\author{
Ryuichi FukUYama and Nobuyoshi Shimizu* \\ Department of Molecular Biology, Keio University School of Medicine, \\ 35 Shinanomachi, Shinjuku-ku, Tokyo 160, Japan
}

\begin{abstract}
Summary Physical mapping of genes by fluorescence in situ hybridization (FISH) has become routine using fluorescein isothiocyanate (FITC) for probe detection and propidium iodide (PI) for chromosome staining. We have modified this conventional FISH method in a way that utilizes Texas red (TR) for signal detection and quinacrine mustard (QM) for chromosome banding. Using this Texas red and quinacrine (TRQ) method, we were able to identify individual acrocentric chromosomes with varying degrees of ribosomal RNA gene clusters. Two acrocentric chromosomes were found to carry extremely small number of rRNA gene copies as compared to the other eight counterparts in human diploid lymphoblastoid cell line GM00130B. Thus, the TRQ method allows one to probe for a specific sequence while identifying individual chromosomes and will be powerful for the chromosomal localization of various genes.
\end{abstract}

Key Words FISH, Texas red, Q-banding, rRNA gene, gene mapping

\section{INTRODUCTION}

Progress in the analysis of the complex human genome depends on mapping of a large number of DNA probes to individual chromosomes. The most advanced method for identifying the chromosomal locus of a human DNA segment is fluorescence in situ hybrizidation (FISH) (Bhatt and Mcgee, 1990). In the widely accepted FISH method, fluorescent signals of FITC are enhanced by counterstaining with PI and identification of individual chromosomes is not possible except R-banding is performed after probe hybridization (Lichter et al., 1989; Viegas-Pequignot et al., 1989; Cherif et al., 1990; Takahashi et al., 1991). At present, no method is available for concurrent chromosome identification and gene localization. Therefore, a rapid and simple technique for chromosome identification compatible with FISH is still required. We examined the possible use of a new combination of

Received March 9, 1992; Accepted April 13, 1992. 
fluorescent dyes. Quinacrine (Q)-banding (Caspersson et al., 1971) was used to identify chromosomes, while biotinylated probes were detected by TR-conjugated streptoavidin. By this combination (TRQ), we were able to determine the size of rRNA gene clusters on individual acrocentric chromosomes in human diploid lymphoblastoid cell line GM00130B. The TRQ method for FISH is simple and accurate and appears useful for physical mapping of human genes.

\section{MATERIALS AND METHODS}

Cell line and chromosome preparation. Human diploid lymphoblastoid cell line GM00130B was maintained as previously described (Minoshima et al., 1990). The karyotype of this line appears normal and stable as indicated (Minoshima et al., 1990). Metaphase chromosome spreads were prepared by the standard colcemid treatment, hypotonic shock and methanol/acetic acid fixation as described (Grill et al., 1985). After RNase treatment, chromosomes were denatured in 70 $\%$ formamide $/ 2 \times \mathrm{SSC}(1 \times \mathrm{SSC}$ is $0.015 \mathrm{~m}$ sodium citrate $/ 0.15 \mathrm{~m}$ sodium chloride, $\mathrm{pH} \mathrm{7.0)}$ ) for $3 \mathrm{~min}$ at $72^{\circ} \mathrm{C}$, followed by dehydration in 70,90 , and $100 \%$ ice-cold ethanol ( 3 min each) and then air dried.

FISH and probe detection. A recombinant plasmid pHr14E3 containing $3^{\prime}$ portion of $18 \mathrm{~S}$ and $5^{\prime}$ portion of $28 \mathrm{~S}$ human $\mathrm{rRNA}$ gene including internal transcribable spacer (Ranzani et al., 1984) was obtained from Japanese Cancer Research Resources Bank. The DNA was nick-translated at $16^{\circ} \mathrm{C}$ for $60 \mathrm{~min}$ in a reaction mixture containing $40 \mathrm{U} / \mathrm{ml}$ DNA polymerase I (BRL, Gaithersburg, Maryland), $68 \mathrm{ng} / \mathrm{ml}$ pancreas DNase I (Sigma, St Louis, Missouri) and biotinylated nucleotides (Biotin-7-dATP, BRL or Biotin-11-dCTP, ENZO, New York). Biotin-labeled probes were ethanol-precipitated, dissolved in a hybridization mixture $(50 \%$ formamide $/ 2 \times \mathrm{SSC} / 10 \%$ dextran sulfate, $1 \mathrm{mg} / \mathrm{ml}$ bovine serum albumin (BSA) (Boehringer, Mannheim, FRG) and hybridized as described (Lichter et al., 1989). After post-hybridization washes and blocking with $5 \%$ nonfat dry milk (BRL) in phosphate buffered saline (PBS, pH 7.5), the probe was detected by means of FITCconjugated avidin DN (FITC-AV, Vector Laboratories, Burlingame, California) or Texas red-conjugated streptoavidin (TR-SAV, Gibco BRL). The intensity of biotin-linked fluorescence was amplified by adding a layer of biotinylated goat anti-avidin antibody (Vector Lab.), followed by another layer of FITC-AV or TRSAV.

Counterstain of chromosome. Chromosomes were counterstained with PI ( $5 \mu \mathrm{g} / \mathrm{ml}$ in PBS) for $3 \mathrm{~min}$ in the case of FITC-AV or with QM (Sigma, $10 \mu \mathrm{g} / \mathrm{ml}$ in

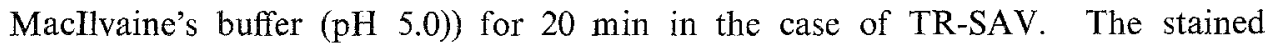
chromosome slides were washed without dyes for $30 \mathrm{~min}$ with vigorous shaking. We used low concentrations of QM $(10 \mu \mathrm{g} / \mathrm{ml})$ to avoid overstaining. Q-bands and Texas red fluorescence were stable in Macllvaine's buffer ( $\mathrm{pH}$ 5.0) for several days.

Laser scanning microscopy. The FITC, TR, QM, and PI were excited by an argon ion laser equipped on the MRC-600 system (Bio-Rad, Richmond, California). 


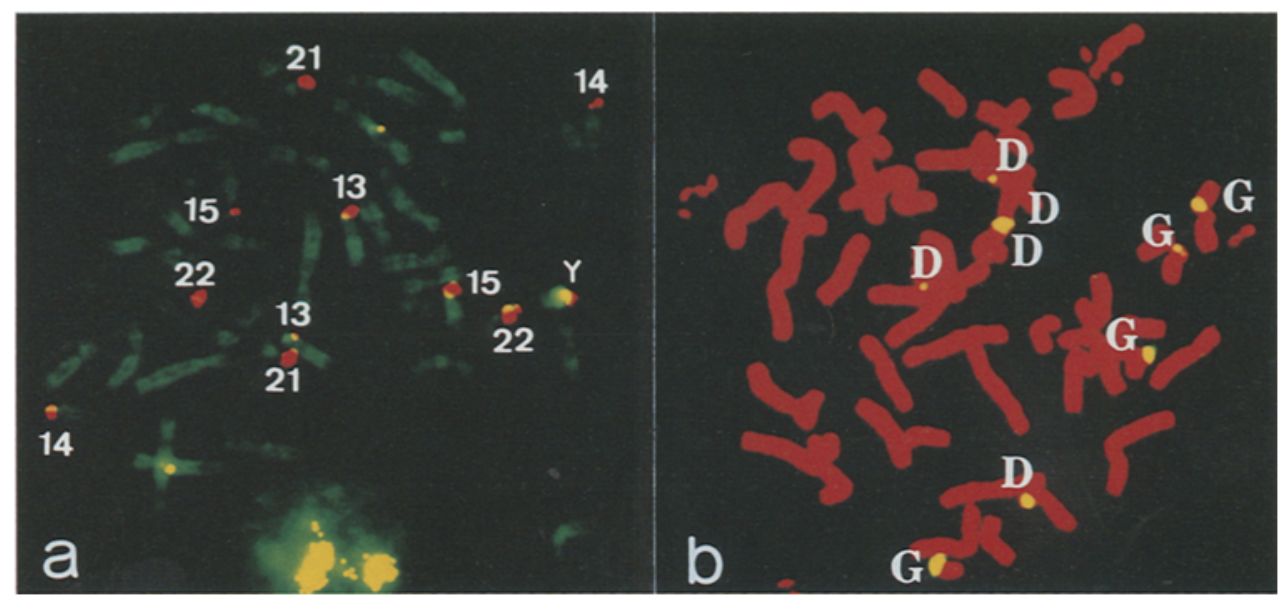

Fig. 1. (A) Identification of rRNA gene cluster regions by TRQ method with pHr14E3 as the probe. Numbers indicate D- and G-group chromosomes. (B) Detection of rRNA gene cluster regions by the conventional FISH method with $\mathrm{pHr}$ $14 \mathrm{E} 3$ as the probe. D, D-group chromosomes; $\mathrm{G}, \mathrm{G}$-group chromosomes.

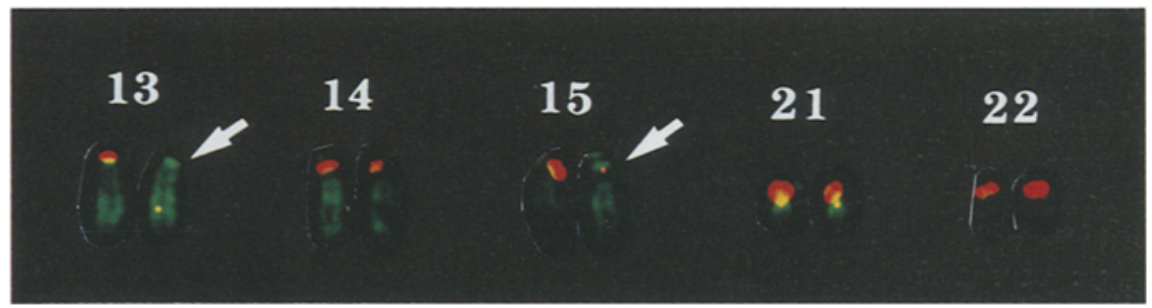

Fig. 2. Identification of $\mathrm{TRNA}$ gene cluster regions by TRQ method with $\mathrm{pHr} 14 \mathrm{E} 3$ as the probe. Two chromosomes 13 and 15 exhibit the lowest signal intensities (arrows).

The fluorescence of FITC and QM, and fluorescence of TR and PI were detected by different photomultipliers after passing through specific emission filters $(540$ $\mathrm{nm}$ for FITC and QM, $600 \mathrm{~nm}$ for TR and PI, respectively). Thus, two separate images were obtained from the same slide and merged by computer graphics. They were photographed by MULTI SCAN (Toshiba, Tokyo).

\section{RESULTS}

We examined optimal conditions of QM counterstaining after detection of the hybridized probe by TR. This TRQ method was compared with a conventional FISH method which utilizes FITC and PI. The rRNA gene cluster was used as a model system for this comparison. The conventional FISH method yielded high levels of signal intensity on ten acrocentric chromosomes, but no banding information was obtained due to the homogeneous staining of chromosomes 
(Fig. 1B). On the other hand, the TRQ method showed substantial fluorescent signals on the well banded chromosomes (Fig. 1A). Both methods revealed significant variations in the size of rRNA gene clusters among these chromosomes. The conventional FISH method revealed two D-group chromosomes as having the smallest rRNA gene clusters and the TRQ method identified these chromosomes as chromosomes 13 and 15 (Fig. 2, arrows).

\section{DISCUSSION}

We have successfully utilized a modified FISH method to rapidly recognize chromosomal banding pattern together with localization of fluorescent signals of DNA probes. Several FISH methods are available for the regional mapping of genes but these methods utilize post R-banding with or without Giemsa (ViegasPequignot et al., 1989; Lichter et al., 1989; Cherif et al., 1990; Takahashi et al., 1991) or pre-banding with Giemsa (Edwards et al., 1990). G-banding requires relocation of specific metaphase spreads and two separate photographic steps. Rbanding requires bromo-deoxyuridine treatment of cell cultures followed by UV irradiation and incu'bation with hot alkali (Therman, 1985). Q-banding used here has a number of advantages in its rapidity, easiness, and accuracy. The Q-banding has been successfully used for in situ hybridization in conjunction with radio-labeled probes (Shinkai et al., 1989; Weremowicz et al., 1990). Yet, radio-labeling is time consuming and requires statistical consideration. We used TR to detect signals of probes on the Q-banded chromosomes by the aid of laser scanning microscope and image analysis.

The copy number of rRNA gene is known to vary among chromosomes belonging to D- and G-groups (Ranzani et al., 1984; Warburton and Henderson, 1979). In GM00130B cells, the conventional FISH method revealed that two D-group chromosomes carry much smaller numbers of rRNA genes than other acrocentric chromosomes (Fig. 1B). The TRQ method identified these chromosomes as one of homologs of chromosomes 13 and 15 (Figs. 1A and 2). The TRQ method clearly demonstrated the substantial variation of rRNA gene copy number among 10 acrocentric chromosomes. The TRQ method will be powerful for simple and rapid localization of various genes to their respective chromosomes.

Acknowledgment We thank Ms Y. Ichijou for technical assistance and Ms H. Harigai for her assistance in manuscript preparation.

\section{REFERENCES}

Bhatt B, Mcgee JO'D (1990): In situ hybridization. In: Polak JM, Mcgee JO'D (eds). Principle and practice. Oxford Sci Pub, New York, pp 149-164

Caspersson T, Lomakka G, Zech L (1971): The 24 fluorescene patterns of human metaphase chromosomes-distinguishing characters and variability. Hereditas 67: 89-102

Cherif D, Julier C, Delattre O, Derre J, Lathrop GM, Berger R (1990): Simultaneous localization 
of cosmids and chromosome R-banding by fluorescence microscopy: Amplification to regional mapping of human chromosome 11. Proc Natl Acad Sci USA 87: 6639-6643

Edwards Y, Williams S, West L, Lipowicz S, Sheer D, Attwood J, Spurr N, Sarkar R, Saha N, Povey S (1990): The polymorphic human DNA sequence D8S8 assigned to 8q13-21.1, close to the carbonic anhydrase gene cluster, by isotopic and non-isotopic in situ hybridization and by linkage analysis. Ann Hum Genet 54: 131-139

Gill GN, Weber W, Thompson DM, Lin C, Evans RM, Rosenfeld MG, Gamou S, Shimizu N (1985): Relationship between production of epidermal growth factor receptors, gene amplification, and chromosome 7 translocation in variant A431 cells. Somat Cell Mol Genet 11: 309318

Lichter P, Tang C-JC, Call K, Hermanson G, Evans GA, Housman D, Ward DC (1989): Highresolution mapping of human chromosome 11 by in situ hybridization with cosmid clones. Science 247: $64-69$

Minoshima S, Kawasaki K, Fukuyama R, Mackawa M, Kudoh J, Shimizu N (1990): Isolation of giant fragments from flow-sorted human chromosomes. Cytometry 11: 539-546

Ranzani GN, Bernini LF, Crippa M (1984): Inheritance of rDNA spacer length variants in man. Mol Gen Genet 196: 141-145

Shinkai Y, Yoshida MC, Maeda K, Kobata T, Murayama K, Yodoi J, Yagita H, Okumura K (1989): Molecular cloning and chromosomal assignment of a human perforin (PFP) gene. Immunogenetics 30: 452-457

Takahashi E, Yamauchi M, Tsui H, Hitomi A, Meuth M, Hori T (1991): Chromosome mapping of the human cytidine-5'-triphosphate synthetase (CTPS) gene to band 1p34.1-34.3 by fluorescence in situ hybridization. Hum Genet 88: 119-121.

Therman E (1985): Human chromosomes. In: Therman E (ed). Structure, behavior, effects. Springer Verlag, New York, pp 32-42

Viegas-Péquignot E, Dutrillaux B, Magdelenat H, Coppey-Moison M (1989): Mapping of singlecopy DNA sequences on human chromosomes by in situ hybridization with biotinylated probes: Enhancement of detection sensitivity by intensified-fluorescence digital-imaging microscopy. Proc Natl Acad Sci USA 86: 582-586

Warburton D, Henderson AS (1979): Sequential silver staining and hybridization in situ on nucleolus organizing regions in human cells. Cytogenet Cell Genet 24: 168-175

Weremowicz S, Fox AE, Morton CC, Vallee BL (1990): The placental ribonuclease inhibitor (R$\mathrm{NH})$ gene is located on chromosome subband 11p15.5. Genomics 8: 717-721 